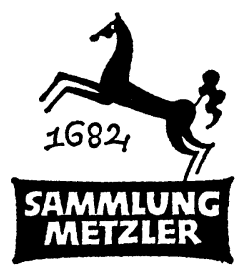

REALIEN ZUR LITERATUR ABT. D:

LITERATURGESCHICHTE 
ANNI MEETZ

\title{
FRIEDRICH HEBBEL
}

3., durchgesebene und ergänate Auflage

\author{
MCMLXXIII \\ J.B. METZLERSCHE VERLAGSBUCHHANDLUNG \\ STUTTGART
}


r. Auflage 1962

2. Auflage 1965

3. Auflage 1973

ISBN 978-3-476-10018-4

ISBN 978-3-476-03805-0 (eBook)

DOI 10.1007/978-3-476-03805-0

M I8

(C) Springer-Verlag GmbH Deutschland 1973

Ursprünglich erschienen bei J.B.Metzlersche Verlagsbuchhandlung und Carl Ernst Poeschel Verlag GmbH in Stuttgart 1962/1973 


\section{IN HALT}

I. Ausgaben (Werke, Tagebücher, Briefe, Nacblaß) . . . . . I II. Leben und Werk . . . . . . . . . . . . 7

r. Wesselburen-Hamburg-Heidelberg-München . . 7

2. "Judith" - "Genoveva" - Kopenhagen . . . . . . 17

3. Paris - »Maria Magdalena «. . . . . . . . . . 34

4. Rom - Neapel . . . . . . . . . . . . 42

5. Wien - "Julia " - "Ein Trauerspiel in Sizilien" . . 45

6. Revolution 1848 - "Herodes und Mariamne« . . . . SI

7. "Der Rubin" - "Michel Angelo« - Erzählungen . . 59

8. "Agnes Bernauer" . . . . . . . . . . . 67

9. "Gyges und sein Ring" . . . . . . . . . . . 73

ro. "Mutter und Kind" - Lyrik - "Die Nibelungen« . . 79

II. "Demetrius« - Ausklang . . . . . . . . 86

III. Gescbicbte, Stand und Aufgaben der Hebbel-Forscbung . . . . 92

Register . . . . . . . . . . . . IO2 


\section{AbKürzungen}

$\begin{array}{ll}\text { Br., T., W. } & =\text { s. S. } 4 \\ \text { DLZ } & =\text { Deutsche Literatur-Zeitung } \\ \text { DVjs. } & =\begin{array}{l}\text { Deutsche Vierteljahrsschrift für Literatur } \\ \text { schaft und Geistesgeschichte }\end{array} \\ \text { Germ. Rev. } & =\text { The Germanic Review } \\ \text { GRM } & =\text { Germanisch-Romanische Monatsschrift } \\ \text { GSA } & =\text { Goethe- und Schiller-Archiv, Weimar } \\ \text { H-Jb. } & =\text { Hebbel-Jahrbuch } \\ \text { Jb. } & =\text { Jahrbuch } \\ \text { PMLA } & =\text { Publications of the Modern Language } \\ \text { RLV } & =\text { Revue des Langues Vivantes } \\ \text { ZfdPh. } & =\text { Zeitschrift für deutsche Philologie }\end{array}$

